\title{
A chiral luminescent liquid crystal with a tolane unit
}

Zhihui Cheng, Ying Zang, Yi Li, Baozong Li, Chuanjiang Hu,

Hongkun $\mathrm{Li}^{*}$ and Yonggang Yang*

State and Local Joint Engineering Laboratory for Novel Functional Polymeric Materials, Jiangsu Key Laboratory of Advanced Functional Polymer Design and Application, College of Chemistry, Chemical Engineering and Materials Science, Soochow University, Suzhou, China

E-mail: hkli@suda.edu.cn; ygyang@suda.edu.cn.

\section{Table of Contents}

Experimental Section

Figure S1. Photographs of $1 \mathrm{TC} 8 *$ at $143{ }^{\circ} \mathrm{C}$ (a) and $135^{\circ} \mathrm{C}$ (b) taken under UV

illumination.

Figure S2. DSC curve of 1TC $8 *$ in the third heating and cooling process at the rate of

$$
5.0{ }^{\circ} \mathrm{C} \min ^{-1} \text {. }
$$




\section{Experimental Section}

\section{General information}

Tetrahydrofuran was distilled from sodium benzophenone ketyl in an atmosphere of nitrogen. 1,3-Dicyclohexylcarbodiimde (DCC) was purchased from Suzhou Highfine Biotech Co., Ltd. (China). 4-Dimethylaminopyridine (DMAP) and (R)-2-octanol were obtained from J \& K Scientific Ltd. (China). All other chemicals were purchased from Sinopharm Group Chemical Reagent Co., Ltd. (China) and used as received without further purification.

FTIR spectroscopy was performed on a Nicolet 6700 spectrometer at $2 \mathrm{~cm}^{-1}$ resolution by averaging over 32 scans. The ${ }^{1} \mathrm{H}$ NMR spectrum was taken on a Varian NMR (400 MHz) spectrometer in DMSO- $d_{6}$ solutions using tetramethylsilane (TMS) as an internal standard at room temperature. Elemental analysis was measured on an EA-1106 instrument. UV-Vis absorption spectra were recorded on an Agilent Cary 5000 UV-Vis-NIR spectrophotometer. Photoluminescence spectra were obtained on a F-2500 FL spectrophotometer. Fluorescence quantum yields ( $\left.\Phi_{\mathrm{F}}\right)$ were determined by a comparative method and using quinine sulfate in $0.1 \mathrm{M} \mathrm{H}_{2} \mathrm{SO}_{4}\left(\Phi_{\mathrm{F}}=54.6 \%\right)$ as the standard.[1] The absorbance of the solutions was maintained at 0.04-0.06 to avoid the internal filter effect. Differential scanning calorimetry (DSC) measurements were conducted on a TA-Q200 under nitrogen at $5.0{ }^{\circ} \mathrm{C} \mathrm{min}^{-1}$. Circular dichroism spectra were recorded in a $0.01-\mathrm{mm}$ quartz cell on an AVIV-410 spectropolarimeter. For the crystalline structure of $\mathbf{1 T C} \mathbf{8}^{*}$, all measurements were made on a Bruker APEX-II CCD X-ray diffractometer by using graphite monochromated Mo Ka $(\lambda=0.071073 \mathrm{~nm})$ at $273 \mathrm{~K}$. The structure was solved in the space group $\mathrm{P} 2{ }_{1} 2{ }_{1} 2_{1}$ by direct methods and refined on $\mathrm{F}^{2}$ using full matrix least-squares methods with SHELXTL version 2008.

\section{Synthesis}

(S)-4-(Octan-2-yloxy)phenol (1) and 4-[(4-methoxyphenyl)ethynyl]benzoic acid (2) shown in Scheme 1 were prepared according to the modified methods reported in our previous work.[2,3] 


\section{Synthesis of (S)-4-(octan-2-yloxy)phenyl 4-((4-methoxyphenyl)ethynyl)benzoate}

(1TC8*). $1.2 \mathrm{~g}$ (5.4 mmol) of $\mathbf{1}$ and $1.63 \mathrm{~g}(6.5 \mathrm{mmol})$ of $\mathbf{2}$ were added into a 500-mL round-bottom flask. Then, $200 \mathrm{~mL}$ of distilled tetrahydrofuran was injected under $\mathrm{N}_{2}$ to dissolve the solid, followed by the addition of $1.3 \mathrm{~g}(6.5 \mathrm{mmol})$ of DCC and appropriate DMAP. The reaction mixture was stirred at $0^{\circ} \mathrm{C}$ for $3 \mathrm{~h}$ and room temperature for another $24 \mathrm{~h}$ under $\mathrm{N}_{2}$. After filtration and solvent evaporation, the crude product was purified by a silica gel column using ethyl acetate/petroleum ether $(1: 20)$ as eluent and recrystallization from acetone/methanol. A white solid of $1 \mathrm{TC} 8^{*}$ was obtained in $30.0 \%$ (0.75 g). FT-IR (KBr pellet): $3071 \mathrm{~cm}^{-1}(\mathrm{C}-\mathrm{H}$ of the phenyl, stretching), $2956 \mathrm{~cm}^{-1}$ ( $\left.v_{\text {asC }-\mathrm{H} 3}\right), 2866 \mathrm{~cm}^{-1}\left(v_{\mathrm{sC}-\mathrm{H} 3}\right), 2923 \mathrm{~cm}^{-1}\left(v_{\text {asC-H2 }}\right), 2854 \mathrm{~cm}^{-1}$ $\left(v_{\mathrm{sC}-\mathrm{H} 2}\right), 2206 \mathrm{~cm}^{-1}\left(v_{\mathrm{C} \equiv \mathrm{C}}\right), 1730 \mathrm{~cm}^{-1}\left(v_{\mathrm{C}=\mathrm{O}}\right), 1599 \mathrm{~cm}^{-1}, 1509 \mathrm{~cm}^{-1}, 1468 \mathrm{~cm}^{-1}\left(v_{\mathrm{Ph}}\right)$. ${ }^{1} \mathrm{H}-\mathrm{NMR}\left(400 \mathrm{MHz}, \mathrm{DMSO}-d_{6}, \mathrm{TMS}, 25^{\circ} \mathrm{C}\right): \delta=0.86\left(\mathrm{t}, 3 \mathrm{H}, J=6.8 \mathrm{~Hz} ; \mathrm{CH}_{3} \mathrm{CH}_{2-}\right)$,

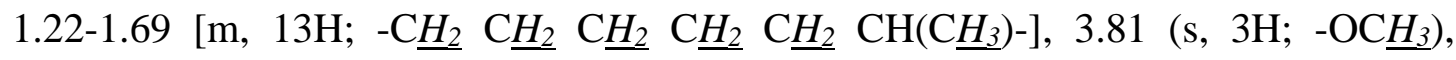
4.39-4.47 (m, 1H; - $\left.\mathrm{CH}_{2} \mathrm{C} \underline{H}\right), 6.98$ (d, $\left.2 \mathrm{H}, J=8.8 \mathrm{~Hz} ; 2,6-\mathrm{Ph}^{H} \mathrm{OCH}_{3}\right), 7.02$ (d, 2H, $J=$ $8.6 \mathrm{~Hz} ; 3,5-\mathrm{Ph} \underline{H O C O}), 7.19$ (d, 2H, $J=8.8 \mathrm{~Hz} ; 2,6-\mathrm{Ph} \underline{H O C O}), 7.57$ (d, 2H, $J=8.8$ $\mathrm{Hz} ; 3,5-\mathrm{Ph} \underline{H O C H})_{3}, 7.73(\mathrm{~d}, 2 \mathrm{H}, J=8.4 \mathrm{~Hz} ; 3,5-\mathrm{COOPh} \underline{H C C}), 8.13$ (d, $2 \mathrm{H}, J=8.4$ $\mathrm{Hz} ; 2,6-\mathrm{COOPh} \underline{H C C}$ ). Elemental analysis calcd for $\mathrm{C}_{30} \mathrm{H}_{32} \mathrm{O}_{4}(\%)$ : C, 78.30; H, 6.94. Found: C, 78.92; H, 7.06.

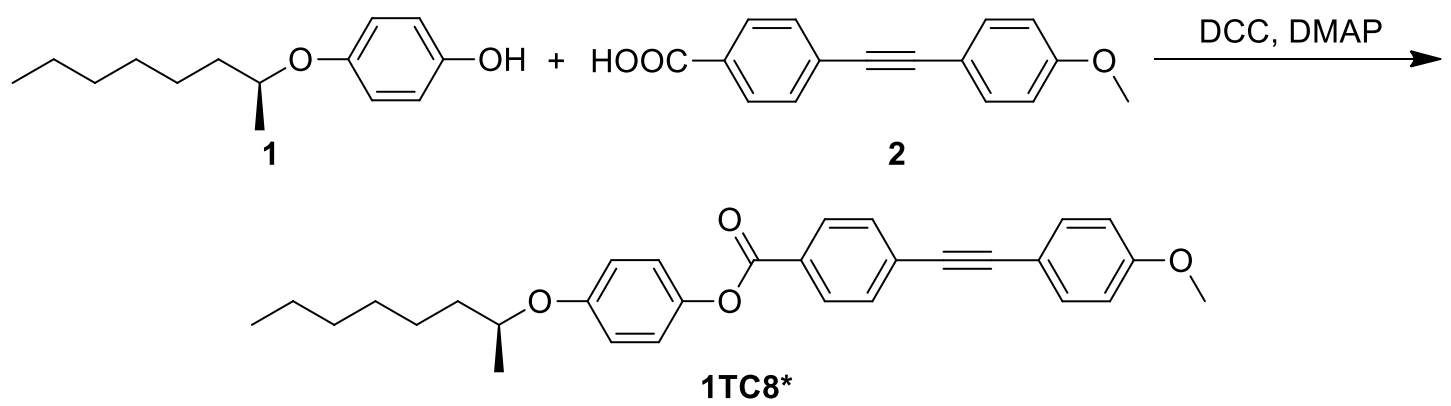

Scheme S1 Synthetic route to $1 \mathrm{TC} 8^{*}$. 

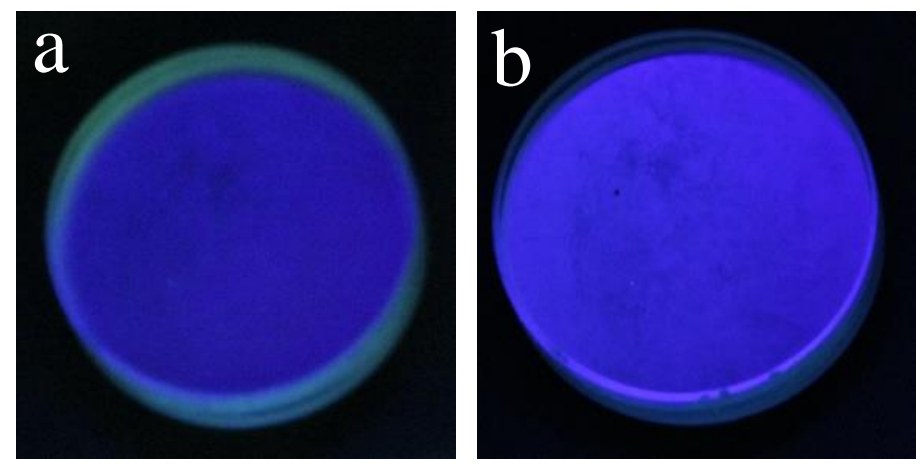

Figure S1. Photographs of $1 \mathrm{TC} 8^{*}$ at $143^{\circ} \mathrm{C}$ (a) and $135^{\circ} \mathrm{C}(\mathrm{b})$ taken under UV illumination.
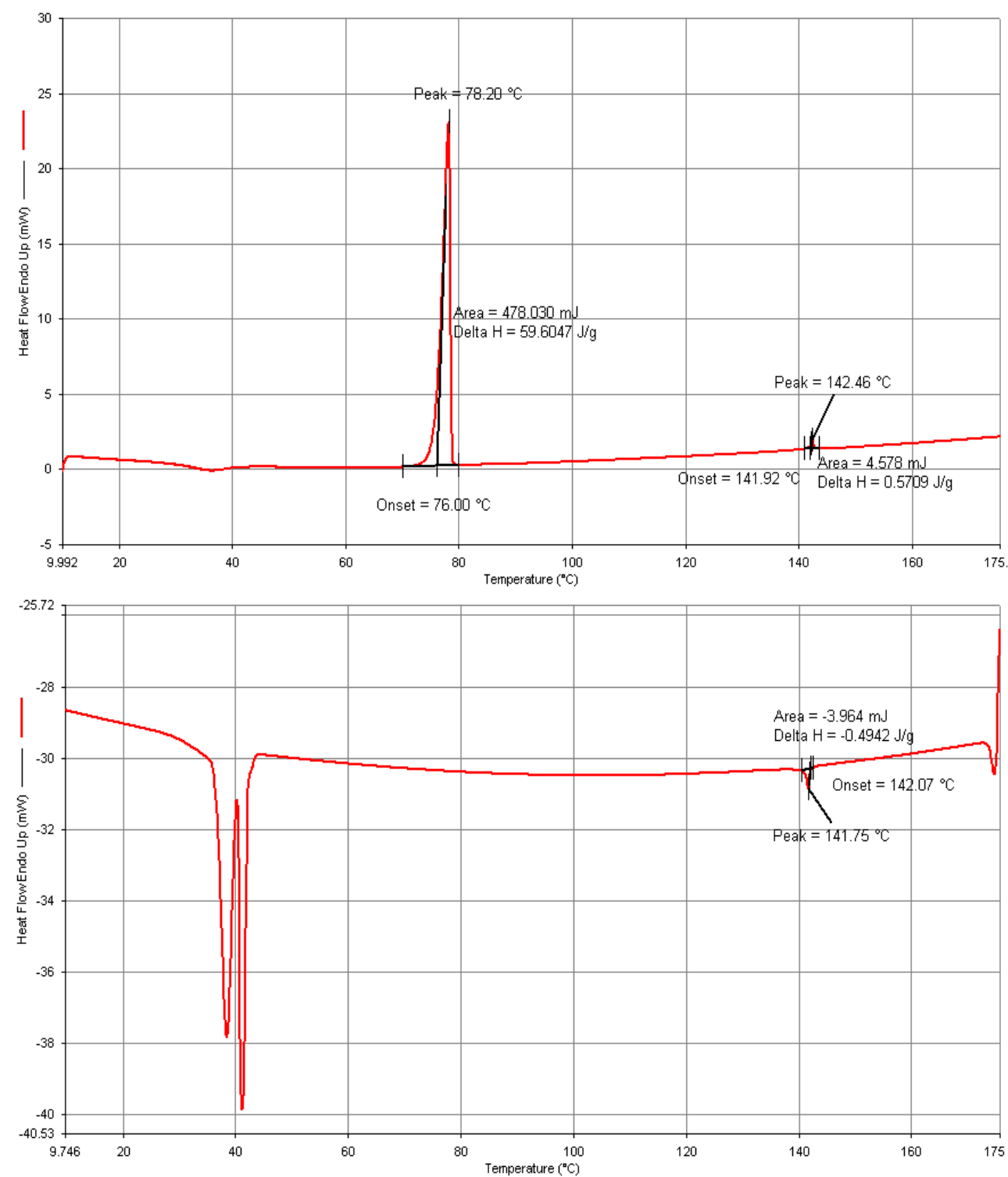

Figure S2. DSC curve of $1 \mathrm{TC} 8 *$ in the third heating and cooling process at the rate of $5.0{ }^{\circ} \mathrm{C} \mathrm{min}-1$. 


\section{References}

[1] Yvon, H. J. A Guide to Recording Fluorescence Quantum Yields.

http://www.horiba.com/fileadmin/uploads/Scientific/Documents/Fluorescence/quantu myieldstrad.pdf.

[2] Yang Y, Li H, Wen J. Synthesis and mesomorphic properties of chiral fluorinated liquid crystals. Liq Cryst. 2007;34:975-979.

[3] Yang Y, Li H, Wen J. Synthesis and mesomorphic properties of some chiral liquid crystals with semifluorinated chains. Mol Cryst Liq Cryst. 2007;469:51-58. 